\title{
Colony-level mechanisms of thermal tolerance regulation in the ant Ectatomma ruidum
}

\author{
Terrence McGlynn ${ }^{1}$, Elizabeth Clifton ${ }^{2}$, Sasha Escamilla ${ }^{1}$, Jade Garcia ${ }^{1}$, Ashley Santizo ${ }^{1}$, \\ and Diana Tafoya ${ }^{1}$ \\ ${ }^{1}$ California State University Dominguez Hills \\ ${ }^{2}$ University of Connecticut
}

December 10, 2020

\begin{abstract}
1. Insects spend energy to function in high temperature environments, and because social insects employ a division of labor, it is likely that thermal tolerance varies among individuals in the colony, based on the tasks that they perform. 2. Foraging workers of the ant Neotropical ant Ectatomma ruidum are known to show temporal differences in thermal tolerance, with greater tolerance in hot afternoons, relative to cool mornings. 3. We developed three hypotheses that can account for temporal differences in thermal tolerance among workers: Thermal Acclimation, Division of Labor, and Circadian Rhythm. 4. We tested these hypotheses with a pair of experiments that involved the measurement of thermal persistence of ants at a constant temperature in time-to-failure assays. The first experiment compared ants with different behavioral roles in colonies, and the second compared colonies subjected to thermal manipulations, then iteratively sampled at daily thermal maxima and minima. 5. We found robust support for the Circadian Rhythm and Thermal Acclimation Hypotheses, and little support for the Division of Labor Hypothesis. Colonies of this species integrate multiple mechanisms of adapting to thermal challenges including time of day, ambient temperature, and the behavioral context of individual workers.
\end{abstract}

Colony-level mechanisms of thermal tolerance regulation in the ant

Ectatomma ruidum

Terry P. McGlynn ${ }^{1,2}$, Elizabeth Clifton $^{3}$, Sasha Escamilla ${ }^{1}$, Jade Garcia $^{1}$, Ashley Santizo ${ }^{1}$, Diana Tafoya ${ }^{1}$

${ }^{1}$ Department of Biology, California State University Dominguez Hills, Carson, CA, USA

${ }^{2}$ Department of Entomology, Natural History Museum of Los Angeles County, Los Angeles, CA

USA

${ }^{3}$ Department of Ecology and Evolutionary Biology, University of Connecticut, Storrs, CT, USA

Corresponding Author: Terry McGlynn; Department of Biology, California State University Dominguez Hills, Carson, CA 90747, USA; terry.mcglynn@gmail.com

McGlynn ORCID: 0000-0002-4290-6156

Clifton ORCID: 0000-0002-3287-1666

Colony-level mechanisms of thermal tolerance regulation in the ant

Ectatomma ruidum

Abstract 
1. Insects spend energy to function in high temperature environments, and because social insects employ a division of labor, it is likely that thermal tolerance varies among individuals in the colony, based on the tasks that they perform.

2. Foraging workers of the Neotropical ant Ectatomma ruidum are known to show temporal differences in thermal tolerance, with greater tolerance in hot afternoons, relative to cool mornings.

3. We developed three hypotheses that can account for temporal differences in thermal tolerance among workers: Thermal Acclimation, Division of Labor, and Circadian Rhythm.

4. We tested these hypotheses with a pair of experiments that involved the measurement of thermal persistence of ants at a constant temperature in time-to-failure assays. The first experiment compared ants with different behavioral roles in colonies, and the second compared colonies subjected to thermal manipulations, then iteratively sampled at daily thermal maxima and minima.

5. We found robust support for the Circadian Rhythm and Thermal Acclimation Hypotheses, and little support for the Division of Labor Hypothesis. Colonies of this species integrate multiple mechanisms of adapting to thermal challenges including time of day, ambient temperature, and the behavioral context of individual workers.

\section{Key words}

circadian rhythm, Costa Rica, division of labor, Formicidae, heat shock protein, social insects, temperature, thermal persistence, tropical rainforest

\section{Introduction}

The rapid anthropogenic warming of the planet has amplified our need to understand how organisms function in challenging thermal regimes. This work is complicated by the broad range of behavioral and physiological mechanisms used for thermoregulation (Kearney, Shine, \& Porter, 2009; McGlynn, Dunn, Wayman, \& Romero, 2010). The behavioral regulation of thermal tolerance is even more complicated in colonies of social insects (Chick, Perez, \& Diamond, 2017). Colonies are comprised of individuals whose thermoregulatory behavior responds to social context (Kaspar, Cook, \& Breed, 2018), even though whole colonies can metabolically function as a single unit (Cook, Kaspar, Flaxman, \& Breed, 2016; Hou, Kaspari, Vander Zanden, \& Gillooly, 2010). It is worthwhile to understand how the sociality of insect colonies may facilitate responsiveness to thermal challenges.

It might be expected that ants are highly capable of flexibly responding to thermal challenges, as they are often regarded as paragons of efficiency (Wilson, 1980). Indeed, ants are capable of responding to thermal challenges at the colony level (Talbot, 1943). In many species, colonies will move to more thermally favorable locations (McGlynn, 2012; Smallwood, 1982). Most of what we know about thermal tolerance in ants comes from interspecific comparisons, among contrasting life histories (Garcia-Robledo, Chuquillanqui, Kuprewicz, \& Escobar-Sarria, 2018), habitats (Kaspari, Clay, Lucas, Yanoviak, \& Kay, 2015), and evolutionary histories (Diamond \& Chick, 2018; Diamond et al., 2012). Because it is energetically expensive to tolerate high heat, ant colonies must experience selective pressures to decrease investment into thermal tolerance for those experiencing cooler temperatures, such as nest-bound workers and foragers that leave the nest in cooler temperatures (Cerdá \& Retana, 2000; Gehring \& Wehner, 1995; Ribeiro, Camacho, \& Navas, 2012; Talbot, 1934; Willot, Gueydan, \& Aron, 2017). In a recent experiment, Villalta et al. (2020) demonstrated how colonies of Aphaenogaster iberica ants move their nests and modify the structure of nests to respond to seasonal temperature changes, and showed that colonies manage thermal challenges through a combination of colony-level behaviors, adaptive physiological responses, and individual foraging decisions. We know less about how intracolonial variation in thermal tolerance is actively managed by colonies.

Physiological mechanisms of thermal tolerance in insects are well described (Harrison, Woods, \& Roberts, 2013). Insects produce heat shock proteins to prevent damage from heat exposure, and ant species that inhabit hotter environments constitutively express more heat shock proteins (Gehring \& Wehner, 1995; Willot et al., 
2017). Heat shock protein production can also be induced by exposure to high heat environments (Helms Cahan et al., 2017; Moseley, 1997). In tropical environments, daily temperature cycles encompass a greater thermal range than annual temperature cycles, which explains why there are differences in thermal tolerance between diurnally-foraging and nocturnally-foraging ant species in the tropics (Garcia-Robledo et al., 2018; Hodkinson, 2005). Some species forage at all times of day, and earlier work with one such species (Ectatomma ruidum ), has shown that foragers sampled in the heat of the day demonstrated a greater thermal tolerance than those sampled in the relative cool of the evening (Esch, Jimenez, Peretz, Uno, \& O'Donnell, 2017). A follow-up study on this disparity found that these differences were not caused by differences between colonies (Nelson et al., 2018). That is, in E. ruidum, differences in thermal tolerance expressed by workers at daily thermal maxima must be accounted for by processes that take place within individual ant colonies. Our present research on E. ruidum is designed to understand the processes that make some workers more thermally tolerant than their nestmates.

Here we hypothesize three mechanisms for colony-level organization of thermal tolerance in E. ruidum . The Thermal Acclimation Hypothesis posits that worker differences in thermal tolerance are the result of ephemeral induced defenses based on prior thermal experiences. The next two hypotheses for the organization of thermal tolerance in ant colonies involve variation in the constitutive expression of thermal tolerance. According to the Division of Labor Hypothesis, variation in thermal tolerance among individuals is explained by their role in the colony (Janowiecki, Clifton, Avalos, \& Vargo, 2020). If this hypothesis is true, then we would expect differences in thermal tolerance between foragers and non-foragers, and between foragers depending on the time of day that they forage. Last, under the Circadian Rhythm Hypothesis, variability in thermal tolerance is driven by an endogenous circadian rhythm (Lazzari \& Insausti, 2008) that regulates daily cycling of heat shock protein production. According to this hypothesis, we expect that the thermal tolerance of ants inside colonies will differ at thermal minima and thermal maxima, even if colonies are exposed to a constant temperature throughout the day. In this study, we challenged ants with a constant elevated temperature and measured the amount of time before they lost the ability to function, which is a measure that we label "thermal persistence." The mechanisms for colony-level regulation of thermal persistence are not necessarily mutually exclusive, and we have no a priori reasons to favor any of the hypotheses over the other. Here we present a set of experiments to evaluate these three hypotheses.

\section{Methods}

Our focal species was the thieving ant, Ectatomma ruidum. This is one of the most common species in the Neotropics, ranging from northern Mesoamerica down to western Amazonia, often occurring extraordinarily high densities (Guénard \& McGlynn, 2013; Santamaría, Armbrecht, \& Lachaud, 2009). This species has been characterized as thermophilic, as it is successful in areas with ample sunlight and foraging occurs even during the hottest times of the day (McGlynn et al., 2010). With a generalized diet (Jandt, Hunt, \& McGlynn, 2015) and moderately-sized colonies of about 200 workers that can be collected in their entirety (Jandt et al., 2015), it is readily maintained in captivity. Workers are about $10 \mathrm{~mm}$ long, so they are large enough to individually mark, observe, and subject to thermal assays.

Workers in E. ruidum forage outside their nests throughout a home range that typically covers several square meters, and foragers are typically generalists that mostly hunt for arthropods, but also collect seeds and nectar (Jandt et al., 2015). From earlier experiments, it is known that foragers represent a only a small fraction of the total number of ants in the colony, and based on marking of individuals, foragers will remain in this role for at least several weeks (Guénard \& McGlynn, 2013). While workers are observed foraging at all times of day, it is not known if there is a division of labor between foragers that forage diurnally and those that forage nocturnally. While foragers are active in very hot conditions, colonies in these sunny areas will preferentially relocate their nests underneath shade by excavating a new nest and abandoning the old one when shade is provided (McGlynn et al., 2010).

Work was conducted at La Selva Biological Station, located in the Caribbean lowlands of northeastern Costa Rica $\left(10.4306^{\circ} \mathrm{N}, 84.0070^{\circ} \mathrm{W}\right)$ in May-June 2018. La Selva is located in a lowland tropical wet forest that receives about four meters of rainfall annually, the bulk of which arrives during the wet season between 
June and December (McDade, Bawa, Hespenheide, \& Hartshorn, 1994). We conducted work during typical weather for the start of the wet season, with frequent but irregular rainfall and a sharp daily increase in temperature in the afternoon. Experiments were conducted with ant colonies located on periphery of the laboratory clearing, located under partial canopy cover.

Our principal response variable in this study is the capability of ants to withstand a constant challenging temperature. We measured this in a time-to-failure assay, which we henceforth refer to as "thermal persistence." We chose this approach because it is most representative of the biological phenomena we are investigating. After pilot experiments, we chose against estimating critical thermal maxima $\left(\mathrm{CT}_{\max }\right)$ because this approach produces little intraspecific variance in this species (Esch et al., 2017; Nelson et al., 2018) and there is poor reproducibility (Ribeiro et al., 2012). In the thermal persistence assay, ants were individually loaded into 2 $\mathrm{mL}$ plastic microcentrifuge tubes and subjected to a constant temperate of $42^{\circ} \mathrm{C}$ in a heating/cooling block (Tropicooler 260014, Boekel Scientific, Feasterville, PA, USA). We evaluated whether the ants were capable of maintaining a righting response upon rotation, in $1 \mathrm{~min}$ intervals. (The microcentrifuge tube containing the ant was removed from the heating block, held horizontally, and was rotated for about 3 seconds at a rate of about 2 revolutions per second, and we assessed whether the ant remained standing during rotation. When the ant failed to demonstrate a righting response at the interval, the threshold time in minutes was recorded.) Throughout this study, the persistence time before failing the righting response ranged between 3-35 min. The same researcher (JG) performed all assays to maintain consistency in the protocol for the righting response assay. After trials, ants were removed from the tubes and recovered in a lidded plastic container, and then were euthanized at $4^{\mathrm{O}} \mathrm{C}$, as returning them to their nestmates would have interfered with the validity of the experiment.

We conducted two experiments. In the first, henceforth "the marking experiment," we evaluated the thermal persistence of ants based on their behavioral role in colonies, indicated by foraging activity and position in the nest in the field. We found and marked nests of 11 colonies in the field. Over the course of a minimum of two days, we marked foraging workers on the gaster with Testor's Enamel (Vernon Hills, IL), with colors to indicate to thermal maximum (early afternoon) or thermal minimum (early in the morning). This marking technique has been routinely used for this purpose and does not appear to interfere with behavior (Breed, McGlynn, Stocker, \& Klein, 1999; McGlynn, Shotell, \& Kelly, 2003) and our pilot trials indicated it does not interfere with thermal persistence assays. After marking, workers were allowed to return to their nests and we continued to mark colonies to exhaustion (until all foraging workers were observed with a mark). We then excavated colonies with care to collect all of the individuals and brood in the nests. E. ruidum nests are typically composed of a vertical series of chambers, each one separated from its neighbor by a passageway. Colonies typically have 4-6 such chambers. We separated the ants from the two uppermost chambers of the nest from those in the lower chambers, to use as an additional variable of behavioral role in the colony. Ants were housed in the laboratory in $120 \mathrm{~mm}$ wide cylindrical polypropylene containers (nest boxes) with a tight-fitting polypropylene lid in shade at ambient temperature, each colony in their own container, provided with water and stray insects as food once in the evening. These nest boxes were opaque and did not permit light. Within a few hours of collection in early afternoon, we conducted the thermal persistence assay on workers, taking care to complete trials on a single colony within a time period of a few hours.

In the second experiment, henceforth the "circadian rhythm experiment," we manipulated the thermal environment of colonies to evaluate the capacity of workers to acclimate to new thermal regimes, and to test for the effect of a circadian rhythm. We marked 10 pairs of colonies in the field. We then excavated one colony per pair, leaving the other colony from each pair in the field to provide workers for control assays run concurrently with the excavated colonies. Each excavated colony was then divided into three equivalent colony fragments, housing them in the same type of chambers used in the prior experiment. For each set of colony fragments corresponding to each colony, we randomly assigned them to one of three treatments: ambient, ambient $+3^{\mathrm{O}} \mathrm{C}$, and constant $24^{\circ} \mathrm{C}$. Over a minimum of three days, we performed thermal persistence assays on workers in colony fragments from all treatments at two time points in each day, at the daily thermal minima (04:30-06:30) and daily thermal maxima (12:30-14:00). These assays included ants from the untreated paired colony in the field as a control for artifacts of the laboratory manipulations. Each batch of 
assays included 16 ants with equal sample sizes of treatments distributed evenly among two colonies.

All analyses were conducted in R (R Core Team, 2020), including the "tidyverse" set of packages (Wickham et al., 2019). We used simple linear Cox Proportional Hazard Analyses (Lin \& Wei, 1989), with the "survival" package (Therneau, 2020) to evaluate differences in time-to-failure in the thermal persistence assays. Proportional Hazard analyses generate a hazard ratio, in which values above 1 indicate a lower time-to-failure relative to a reference. In this instance, low hazard ratios indicate relatively greater capacity to persist at a challenging temperature, and colonies high hazard indicate an earlier failure of the thermal persistence assay. None of the samples were censored in these analyses, as all variates represented ants that were observed until failure to perform.

\section{Results}

In the marking experiment, the main prediction of the Division of Labor Hypothesis was not supported, as we found no difference in thermal persistence between foragers that forage near the thermal maxima and those foraging near the thermal minima (Figure 1; Table 1). However, foragers demonstrated a higher thermal persistence than non-foragers, which is consistent with the Thermal Acclimation Hypothesis. Ants found in lower chambers of the nest had a lower thermal persistence than those collected from the higher chambers of the nest (Figure 2; Table 1), which could potentially be explained by either Acclimation or Division of Labor. There was not a strict division of labor between ants foraging during thermal maxima and those foraging during thermal minima, as several workers were marked at both time points (Figure 1). Nonetheless, their frequency was far lower than expected by random temporal distribution (Fisher's Exact Test, $\mathrm{p}<0.0001)$. We separately tested for differences in thermal persistence among the 11 colonies in this experiment. One colony had an appreciably greater thermal persistence, and this difference was manifested in the whole model analysis (Table S1; Figure S2; Wald test $\mathrm{X}^{2}=19.04, \mathrm{df}=10, \mathrm{p}<0.04 ; \mathrm{N}=399$ ).

In the circadian rhythm experiment, results indicated short-term colony thermal acclimation as well as circadian regulation of thermal persistence (Figure 3; Table 2). Colonies kept at temperatures above ambient demonstrated greater thermal persistence than those maintained at ambient, and colonies maintained at a cooler constant temperature demonstrated lower thermal persistence. Thermal persistence was different between the thermal maxima and the thermal minima, in all treatments, and particularly so under constant conditions. This effect of time of day was not found in field-collected foragers. The performance of workers removed from colony fragments every 12 hours over the time series did not atrophy over the duration of trials for up to four days, indicating that the results are not a spurious consequence of performance during captivity (Figure S1). As in the marking experiment, we separately tested for differences in thermal persistence among the 11 colonies in the experiment. Two colonies had an appreciably lower thermal persistence than the others (Table S2; Figure S3; Wald test $\mathrm{X}^{2}=21.7=$, $\mathrm{df}=10, \mathrm{p}<0.01 ; \mathrm{N}=402$ ).

\section{Discussion}

We found strong support for Circadian Rhythm and Thermal Acclimation Hypotheses, indicating that colonies of Ectatomma ruidumdynamically manage constitutive and induced mechanisms of thermal tolerance. When we altered the thermal regime experienced by these ant colonies, the thermal persistence of workers responded accordingly, consistent with the Thermal Acclimation Hypothesis. Simultaneously, colonies demonstrated overt diel shifts in thermal persistence in the absence of external temporal cues, supporting the Circadian Rhythm Hypothesis. While we found some differences in thermal performance associated with behavioral roles, the Division of Labor Hypothesis could not account for differences in thermal persistence based on time of day, even though that was the prior finding that led us to conduct the present study (Esch et al., 2017; Nelson et al., 2018). The authors of the earlier studies wondered how colonies of E. ruidum managed the thermal tolerance of foragers associated with diel changes in temperature. Our answer to that question is that a constitutive division of labor is not as important of a mechanism as circadian rhythms and proximate acclimation to recent thermal exposure.

We were surprised by the small magnitude of the findings. The statistical significance of the results is robust, so we have little doubt that these are real biological phenomena. Nevertheless, the differences among 
sample populations were not so great. This is consistent with the hypothesis that hotter and less seasonal environments result in narrow thermal limit ranges (Kaspari et al., 2015). It does not appear that the changes are driven by a number of outlying individuals with extreme differences, because in Figures 1 and 2, it appears that the entire distributions are shifted. We think that the biological significance of our findings is not that these tropical ants are responding to their thermal environment with massive physiological changes, but rather that these ants have the capacity to demonstrate flexibility in a relatively complex manner. We did not press hard on thermal levers to exert stresses on these ants. The marking experiment simply measured existing differences among ants occurring in the wild, and the colony fragments in the circadian rhythm experiment were only held in the laboratory for up to four days. The only treatment with a more-than-slight thermal stress (cooling a tropical rain forest species to a constantly air-conditioned environment) produced an effect of substantial magnitude. We expect that subjecting these ants to greater thermal extremes will result in more marked effects.

The discovery of a circadian rhythm appears to be a relatively novel result. Thermal tolerance is known to follow circadian rhythms in some prokaryotes and plants (Rensing \& Monnerjahn, 1996), but to our knowledge has not yet been documented in any insects. Because some animals regulate heat shock proteins following the seasons (Arad, Mizrahi, Goldenberg, \& Heller, 2010; Bujan, Roeder, Yanoviak, \& Kaspari, 2020), it makes sense that tropical rain forest insects are also capable of recapitulating this activity over a 24 hour period, =he time scale during which they experience the greatest range of thermal challenges (Janzen, 1967).

In all treatments, thermal persistence was greater at dawn (the daily thermal minima) than the early afternoon (the daily thermal maxima). We were primed to expect the opposite result, because Esch et al. (2017) and Nelson et al. (2018) reported that ants foraging in the heat of the afternoon demonstrated higher thermal tolerances. In the circadian rhythm experiment, our controls were foragers freshly sampled from the field, which constitutes a near-replication of those earlier studies with a greater sample size, and we found a non-significant result in the opposite direction. After having had an opportunity to digest the results from the treatments in the Circadian Rhythm experiment, we have landed on a working hypothesis. The well documented mechanism of thermal tolerance for these ants is the production of heat shock proteins, which are both energetically expensive and are consumed as they are used to prevent tissue damage from heat (Feder \& Hofmann, 1999; Moseley, 1997). The production of heat shock proteins must happen prior to the moment of heat exposure, so their production must be made in anticipation of future need. Ants living in a tropical rain forest, including E. ruidum, live with absolute certainty that evenings will bring cool temperatures and the following day will bring heat. Based on our findings, we expect that these ants upregulated heat shock proteins at the start of the day, which effectively anticipates the thermal challenges of a new day. While they know that it will get hot, the extent of the heat and the timing of it throughout the day are not as predictable (Sanford Jr, Paaby, Luvall, \& Phillips, 1994), so acclimation matters too. This working hypothesis is consistent with our finding that ant colonies subjected to a constant cool temperature have extremely low thermal persistence in the afternoon. We interpret this to mean that level of heat shock protein production, while governed in part by a circadian rhythm, can be downregulated once colonies experience consistently low temperatures. To gain a greater understanding of how this circadian rhythm works, further work using more extreme thermal manipulations and more frequent time steps will flesh out the nature of this daily rhythm, as well as work to measure heat shock protein and heat shock protein gene expression. Other ant species have already been shown to upregulate heat shock protein gene expression in response to heat exposure (Nguyen, Gotelli, \& Cahan, 2016), so this is a tenable future line of investigation.

While our finding of higher thermal tolerance in the early morning contradicts earlier published results (Esch et al., 2017; Nelson et al., 2018), we believe this makes sense in light of our other findings. While we conducted our project in the same field site as Nelson et al. (and even used the same heating/cooling device), both earlier papers were conducted over a single 24 hour period during the dry season (which has cooler temperatures), while the present study was conducted over a longer duration in the wet season (which is characteristically hotter). Moreover, the low-temperature sampling by Esch et al. (2017) happened several hours before the thermal maxima, and the sampling by Nelson et al. (2018) was between 04:00 and 04:30, 
whereas our sampling occurred 04:30-06:30. Our slightly later sampling was marginally closer to the thermal minima, but not to an extent that we think the temperature difference would matter. Nonetheless, if our working hypothesis that heat shock protein production is upregulated at the start of the day is correct, then this time difference could possibly explain why our early morning ants demonstrated greater thermal tolerance.

We found that foragers have greater thermal persistence than non-foragers. However, is not the essential prediction of our Division of Labor hypothesis, which was that there would be differences thermal persistence between foragers that ventured into the heat of the afternoon and those that foraged in the cool of the early morning. The difference between foragers and non-foragers is more parsimoniously explained by Thermal Acclimation. In the marking experiment, we noticed that the mean difference in thermal persistence between foragers and non-foragers was three minutes, which is same magnitude of difference in the thermal minima assays for the circadian rhythm experiment, between freshly caught control foragers and laboratory colony ants. This suggests that both the thermal treatment on colonies as well as the artifacts of the laboratory manipulation did not alter thermal persistence in the thermal minima time step, and that the effect of the treatment was contingent on the circadian rhythm.

While our experiment was not designed with the purpose of assessing intercolonial differences in thermal persistence, these comparisons were possible with our sampling design. We separately compared the thermal tolerances of colonies from the two experiments, and found that workers from 3 of 21 colonies demonstrated significantly greater thermal persistence. By random chance, 1 out of 20 colonies is expected to generate a p-value below 0.05, and we don't think that adding just 2 more colonies constitutes compelling evidence, as it looks more like a few lucky rolls on a 20 -sided die. We selected our colonies intentionally so that they were in as similar environments to one another as possible (with respect to light exposure in particular), because this was a lurking variable that we sought to control. That we detected any differences between colonies even though we sought to prevent them from occurring suggests there is greater ambient variation, especially considering the abundance and extremely broad geographic range of this species. Perhaps if we intentionally sampled for thermal heterogeneity in the field and subjected colonies to thermal treatments, this would not only affect colony movement behavior as found in an earlier study (McGlynn et al., 2010), but also shifts in the thermal persistence of colony members.

With respect to climate change, one central concern is the extent of behavioral flexibility, ecological plasticity, and evolutionary lability available to animals facing new thermal challenges. Heat genuinely prevents ants from foraging, as ants will avoid resource-rich areas if they cannot withstand the thermal stresses (Spicer et al., 2017). Thermal limits are a major factor in structuring species distributions across broad environmental gradients (Diamond et al., 2012). Ants also adapt their thermal tolerance to local conditions (Bujan \& Kaspari, 2017; Diamond, Chick, Perez, Strickler, \& Martin, 2017; Villalta et al., 2020); we have known this ever since Mary Talbot invented equipment and protocols to measure critical thermal maxima (Talbot, 1943). In temperate environments, it appears that the ability to withstand cold may be more predictive of distributions than the ability to withstand heat (Bishop, Robertson, Van Rensburg, \& Parr, 2017; Bujan, Roeder, de Beurs, Weiser, \& Kaspari, 2020). In the tropical climates where the most species occur, however, we have many open questions about how biodiversity will respond to rising temperatures (Jenkins et al., 2011). We argue that an integrative understanding of organisms, including the functional ecology at the colony level, will be critical for developing more informative models as the world continues to heat up.

Animals living in social groups are capable of leveraging the modularity of their colonies to efficiently organize behavioral responses to thermal challenges. While this is well known from other social insects, particularly honey bees (for example, Cook \& Breed, 2013; Cook et al., 2016; Kaspar et al., 2018; Stabentheiner, Kovac, \& Brodschneider, 2010), we think that a greater research investment into intracolonial mechanisms of thermal tolerance in ants is necessary to understand the distribution of thermal tolerance at higher levels of organization. With the projected levels of warming that we will experience over at least the next few generations (IPCC, 2014), and the criticality of ants for ecosystem processes (Del Toro, Ribbons, \& Pelini, 2012), we need to understand colony-level processes of thermal management appears foundation to conservation 
planning for these animals.

\section{Data availability}

Data and all associated code are uploaded to Dryad.

\section{Acknowledgements}

Funding was provided by the National Science Foundation (HRD-1826490), the US Department of Education HSI-STEM grant, and a California State University Dominguez Hills RSCA award, and a Graduate Student Fellowship from the Organization for Tropical Studies (OTS). We would like to thank the staff of the OTS, particularly Danilo Brenes and Bernal Matarrita, for their immeasurable support. We thank E. Kuprewicz for advice on analysis, R.F. de Caña and J.E. Watkins for field supplies, and the Urban Nature Research Center of the Natural History Museum for feedback on the manuscript, including K. Bell, B. Brown, A. Clause, M. Connolly, G. Pauly, A. Schulz, and J. Vendetti. This work was conducted under a research permit issued by the Costa Rican Ministry of Energy and Environment.

\section{Authors' contributions}

TPM and EC secured funding; all authors conceived the ideas and designed methodology; all authors collected the data; TPM and EC analyzed the data; TPM led the writing of the manuscript. All authors contributed to drafts and gave final approval for publication.

\section{Literature Cited}

Arad, Z., Mizrahi, T., Goldenberg, S., \& Heller, J. (2010). Natural annual cycle of heat shock protein expression in land snails: Desert versus Mediterranean species of Sphincterochila. Journal of Experimental Biology . doi: 10.1242/jeb.047670

Bishop, T. R., Robertson, M. P., Van Rensburg, B. J., \& Parr, C. L. (2017). Coping with the cold: minimum temperatures and thermal tolerances dominate the ecology of mountain ants. Ecological Entomology . doi: 10.1111/een.12364

Breed, M. D., McGlynn, T. P., Stocker, E. M., \& Klein, a. N. (1999). Thief workers and variation in nestmate recognition behavior in a ponerine ant, Ectatomma ruidum. Insectes Sociaux , 46 (4), 327-331. doi: $10.1007 / \mathrm{s} 000400050153$

Bujan, J., \& Kaspari, M. (2017). Nutrition modifies critical thermal maximum of a dominant canopy ant. Journal of Insect Physiology . doi: 10.1016/j.jinsphys.2017.08.007

Bujan, J., Roeder, K. A., de Beurs, K., Weiser, M. D., \& Kaspari, M. (2020). Thermal diversity of North American ant communities: Cold tolerance but not heat tolerance tracks ecosystem temperature. Global Ecology and Biogeography . doi: 10.1111/geb.13121

Bujan, J., Roeder, K. A., Yanoviak, S. P., \& Kaspari, M. (2020). Seasonal plasticity of thermal tolerance in ants. Ecology . doi: 10.1002/ecy.3051

Cerdá, X., \& Retana, J. (2000). Alternative strategies by thermophilic ants to cope with extreme heat: Individual versus colony level traits.Oikos . doi: 10.1034/j.1600-0706.2000.890117.x

Chick, L. D., Perez, A., \& Diamond, S. E. (2017). Social dimensions of physiological responses to global climate change: What we can learn from ants (Hymenoptera: Formicidae). Myrmecological News .

Cook, C. N., \& Breed, M. D. (2013). Social context influences the initiation and threshold of thermoregulatory behaviour in honeybees.Animal Behaviour . doi: 10.1016/j.anbehav.2013.05.021

Cook, C. N., Kaspar, R. E., Flaxman, S. M., \& Breed, M. D. (2016). Rapidly changing environment modulates the thermoregulatory fanning response in honeybee groups. Animal Behaviour . doi: 10.1016/j.anbehav.2016.03.014 
Del Toro, I., Ribbons, R. R., \& Pelini, S. L. (2012). The little things that run the world revisited: A review of ant-mediated ecosystem services and disservices (Hymenoptera: Formicidae). Myrmecological News .

Diamond, S. E., \& Chick, L. D. (2018). The Janus of macrophysiology: Stronger effects of evolutionary history, but weaker effects of climate on upper thermal limits are reversed for lower thermal limits in ants.Current Zoology . doi: 10.1093/cz/zox072

Diamond, S. E., Chick, L., Perez, A., Strickler, S. A., \& Martin, R. A. (2017). Rapid evolution of ant thermal tolerance across an urban-rural temperature cline. Biological Journal of the Linnean Society ,121 (2), 248-257. doi: 10.1093/biolinnean/blw047

Diamond, S. E., Sorger, D. M., Hulcr, J., Pelini, S. L., Toro, I. Del, Hirsch, C., .. Dunn, R. R. (2012). Who likes it hot? A global analysis of the climatic, ecological, and evolutionary determinants of warming tolerance in ants. Global Change Biology , 18 (2), 448-456. doi: 10.1111/j.1365-2486.2011.02542.x

Esch, C., Jimenez, J. P., Peretz, C., Uno, H., \& O'Donnell, S. (2017). Thermal tolerances differ between diurnal and nocturnal foragers in the ant Ectatomma ruidum. Insectes Sociaux . doi: 10.1007/s00040-017$0555-\mathrm{x}$

Feder, M. E., \& Hofmann, G. E. (1999). Heat-Shock Proteins, Molecular Chaperones, and the Stress Tesponse: Evolutionary and Ecological Physiology. Annual Review of Physiology , 61 (1), 243-282. doi: 10.1146/annurev.physiol.61.1.243

Garcia-Robledo, C., Chuquillanqui, H., Kuprewicz, E. K., \& Escobar-Sarria, F. (2018). Lower thermal tolerance in nocturnal than in diurnal ants: a challenge for nocturnal ectotherms facing global warming. Ecological Entomology . doi: 10.1111/een.12481

Gehring, W. J., \& Wehner, R. (1995). Heat shock protein synthesis and thermotolerance in Cataglyphis, an ant from the Sahara desert.Proceedings of the National Academy of Sciences , 92 (7), 2994 LP - 2998. Retrieved from http://www.pnas.org/content/92/7/2994.abstract

Guénard, B., \& McGlynn, T. P. (2013). Intraspecific Thievery in the Ant Ectatomma ruidum is Mediated by Food Availability. Biotropica ,45 (4), 497-502. doi: 10.1111/btp.12031

Harrison, J. F., Woods, H. A., \& Roberts, S. P. (2013). Ecological and Environmental Physiology of Insects. In Ecological and Environmental Physiology of Insects . doi: 10.1093/acprof:oso/9780199225941.001.0001

Helms Cahan, S., Nguyen, A. D., Stanton-Geddes, J., Penick, C. A., Hernáiz-Hernández, Y., DeMarco, B. B., \& Gotelli, N. J. (2017). Modulation of the heat shock response is associated with acclimation to novel temperatures but not adaptation to climatic variation in the ants Aphaenogaster picea and A. rudis. Comparative Biochemistry and Physiology -Part A : Molecular and Integrative Physiology . doi: 10.1016/j.cbpa.2016.11.017

Hodkinson, I. D. (2005). Terrestrial insects along elevation gradients: Species and community responses to altitude. Biological Reviews of the Cambridge Philosophical Society . doi: 10.1017/S1464793105006767

Hou, C., Kaspari, M., Vander Zanden, H. B., \& Gillooly, J. F. (2010). Energetic basis of colonial living in social insects. Proceedings of the National Academy of Sciences of the United States of America ,107 (8), 3634-3638. doi: 10.1073/pnas.0908071107

IPCC. (2014). Climate Change 2014: Synthesis Report. Contribution of Working Groups I, II and III to the Fifth Assessment Report of the Intergovernmental Panel on Climate Change. In Ipcc .

Jandt, J. M., Hunt, E. M., \& McGlynn, T. P. (2015). Intraspecific Food-Robbing and Neighborhood Competition: Consequences for Anti- Robber Vigilance and Colony Productivity. Biotropica, in press.

Janowiecki, M., Clifton, E., Avalos, A., \& Vargo, E. L. (2020). Upper thermal tolerance of tropical and temperate termite species (Isoptera: Rhinotermitidae, Termitidae): a test of the climate variability hypothesis in termites. Insectes Sociaux . doi: 10.1007/s00040-019-00727-7 
Janzen, D. H. (1967). Why Mountain Passes are Higher in the Tropics. The American Naturalist . doi: $10.1086 / 282487$

Jenkins, C. N., Sanders, N. J., Andersen, A. N., Arnan, X., Bruhl, C. a., Cerda, X., .. Dunn, R. R. (2011). Global diversity in light of climate change: the case of ants. Diversity and Distributions ,17 (4), 652-662. doi: $10.1111 / \mathrm{j} .1472-4642.2011 .00770 . \mathrm{x}$

Kaspar, R. E., Cook, C. N., \& Breed, M. D. (2018). Experienced individuals influence the thermoregulatory fanning behaviour in honey bee colonies. Animal Behaviour . doi: 10.1016/j.anbehav.2018.06.004

Kaspari, M., Clay, N. A., Lucas, J., Yanoviak, S. P., \& Kay, A. (2015). Thermal adaptation generates a diversity of thermal limits in a rainforest ant community. Global Change Biology . doi: 10.1111/gcb.12750

Kearney, M., Shine, R., \& Porter, W. P. (2009). The potential for behavioral thermoregulation to buffer "cold-blooded" animals against climate warming. Proceedings of the National Academy of Sciences of the United States of America . doi: 10.1073/pnas.0808913106

Lazzari, C. R., \& Insausti, T. C. (2008). Circadian rhythms in insects.

Comparative Aspects of Circadian Rhythms.

Lin, D. Y., \& Wei, L. J. (1989). The robust inference for the cox proportional hazards model. Journal of the American Statistical Association . doi: 10.1080/01621459.1989.10478874

McDade, L. A., Bawa, K. S., Hespenheide, H. A., \& Hartshorn, G. S. (1994). La Selva: ecology and natural history of a Neotropical rain forest. La Selva: Ecology and Natural History of a Neotropical Rain Forest . doi: $10.2307 / 5839$

McGlynn, T. P. (2012). The ecology of nest movement in social insects.Annual Review of Entomology , 57 , 291-308. doi: 10.1146/annurev-ento-120710-100708

McGlynn, T. P., Dunn, T., Wayman, E., \& Romero, A. (2010). A thermophile in the shade: light-directed nest relocation in the Costa Rican ant Ectatomma ruidum. Journal of Tropical Ecology ,26 (05), 559-562. doi: $10.1017 / \mathrm{S} 0266467410000313$

McGlynn, T. P., Shotell, M. D., \& Kelly, M. S. (2003). Responding to a Variable Environment: Home Range, Foraging Behavior, and Nest Relocation in the Costa Rican Rainforest Ant Aphaenogaster araneoides. Journal of Insect Behavior , 16 (5), 687-701. doi: 10.1023/B:JOIR.0000007704.22329.a5

Moseley, P. L. (1997). Heat shock proteins and heat adaptation of the whole organism. Journal of Applied Physiology . doi: 10.1152/jappl.1997.83.5.1413

Nelson, A. S., Scott, T., Barczyk, M., McGlynn, T. P., Avalos, A., Clifton, E., .. O’Donnell, S. (2018). Day/night upper thermal limits differ within Ectatomma ruidum ant colonies. Insectes Sociaux , 65 (1), 183-189. doi: 10.1007/s00040-017-0585-4

Nguyen, A. D., Gotelli, N. J., \& Cahan, S. H. (2016). The evolution of heat shock protein sequences, cisregulatory elements, and expression profiles in the eusocial Hymenoptera. BMC Evolutionary Biology . doi: $10.1186 / \mathrm{s} 12862-015-0573-0$

R Core Team. (2020). A Language and Environment for Statistical Computing. R Foundation for Statistical Computing, Vol. 2, p. https://www.R-project.org. Retrieved from http://www.r-project.org

Rensing, L., \& Monnerjahn, C. (1996). Heat shock proteins and circadian rhythms. Chronobiology International . doi: 10.3109/07420529609020904

Ribeiro, P. L., Camacho, A., \& Navas, C. A. (2012). Considerations for assessing maximum critical temperatures in small ectothermic animals: Insights from leaf-cutting ants. PLoS ONE . doi: 10.1371/journal.pone.0032083 
Sanford Jr, R. L., Paaby, P., Luvall, J. C., \& Phillips, E. (1994). Climate, geomorphology, and aquatic systems. La Selva: Ecology and Natural History of a Neotropical Rain Forest, 19-33.

Santamaria, C., Armbrecht, I., \& Lachaud, J. P. (2009). Nest distribution and food preferences of Ectatomma ruidum (Hymenoptera: Formicidae) in shaded and open cattle pastures of Colombia.Sociobiology , 53 , 517541. doi: www.csuchico.edu/biol/Sociobiology/sociobiologyindex.html

Smallwood, J. (1982). Nest relocations in ants. Insectes Sociaux ,29 (2), 138-147. doi: 10.1007/BF02228747

Spicer, M. E., Stark, A. Y., Adams, B. J., Kneale, R., Kaspari, M., \& Yanoviak, S. P. (2017). Thermal constraints on foraging of tropical canopy ants. Oecologia . doi: 10.1007/s00442-017-3825-4

Stabentheiner, A., Kovac, H., \& Brodschneider, R. (2010). Honeybee colony thermoregulation - Regulatory mechanisms and contribution of individuals in dependence on age, location and thermal stress. PLoS ONE . doi: 10.1371/journal.pone.0008967

Talbot, M. (1934). Distribution of Ant Species in the Chicago Region with Reference to Ecological Factors and Physiological Toleration.Ecology . doi: 10.2307/1932358

Talbot, M. (1943). Response of the Ant Prenolepis Imparis Say to Temperature and Humidity Changes. Ecology . doi: 10.2307/1930536

Therneau, T. M. (2020). A Package for Survival Analysis in R. R Package Verson 3.2-3 . Retrieved from https://cran.r-project.org/package=survival

Villalta, I., Oms, C. S., Angulo, E., Molinas-Gonzalez, C. R., Devers, S., Cerda, X., \& Boulay, R. (2020). Does social thermal regulation constrain individual thermal tolerance in an ant species? Journal of Animal Ecology . doi: 10.1111/1365-2656.13268

Wickham, H., Averick, M., Bryan, J., Chang, W., McGowan, L., Francois, R., .. Yutani, H. (2019). Welcome to the Tidyverse. Journal of Open Source Software . doi: 10.21105/joss.01686

Willot, Q., Gueydan, C., \& Aron, S. (2017). Proteome stability, heat hardening and heat-shock protein expression profiles in Cataglyphis desert ants. Journal of Experimental Biology . doi: 10.1242/jeb.154161

Wilson, E. O. (1980). Caste and division of labor in leaf-cutter ants (Hymenoptera: Formicidae: Atta) - II. The ergonomic optimization of leaf cutting. Behavioral Ecology and Sociobiology . doi: 10.1007/BF00299521

Figure 1. Thermal persistence of foraging and non-foragingEctatomma ruidum ants. Foragers were marked in the field, and whole colonies were collected. Thermal persistence time-to-failure assays were conducted on individual workers, including ants collected from nests that were not marked as foragers. Statistics are in Table 1. 


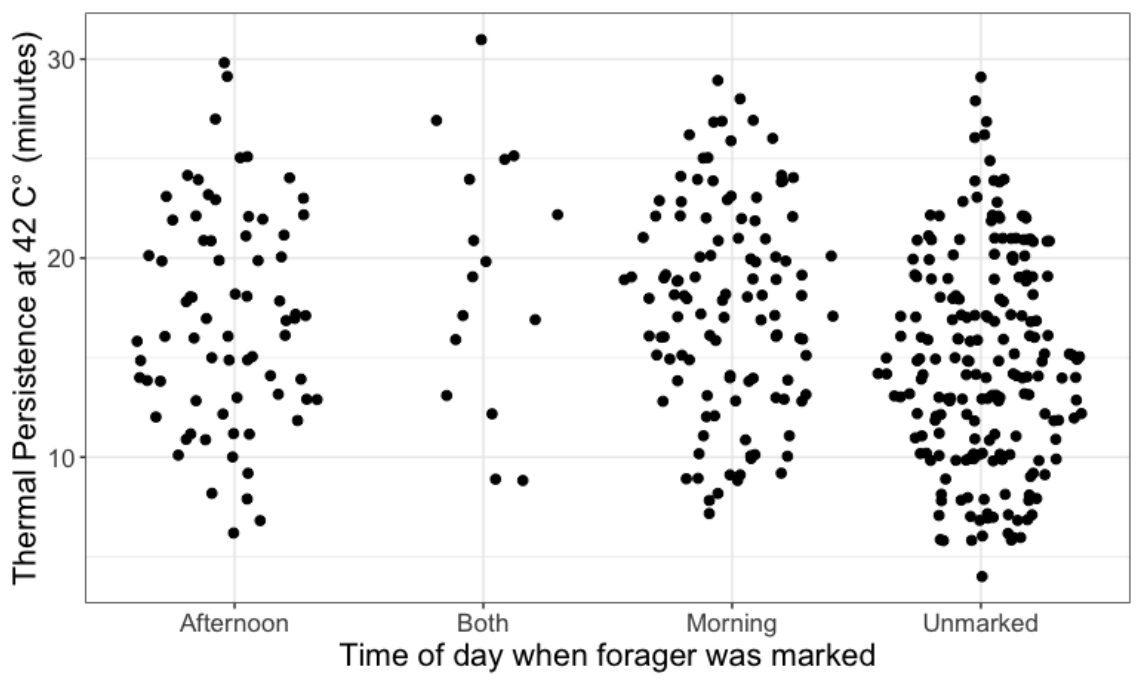

Figure 2. Thermal persistence of Ectatomma ruidum ants based on their location in the nest when it was excavated. Thermal persistence time-to-failure assays were conducted on individual workers, Statistics are in Table 1.

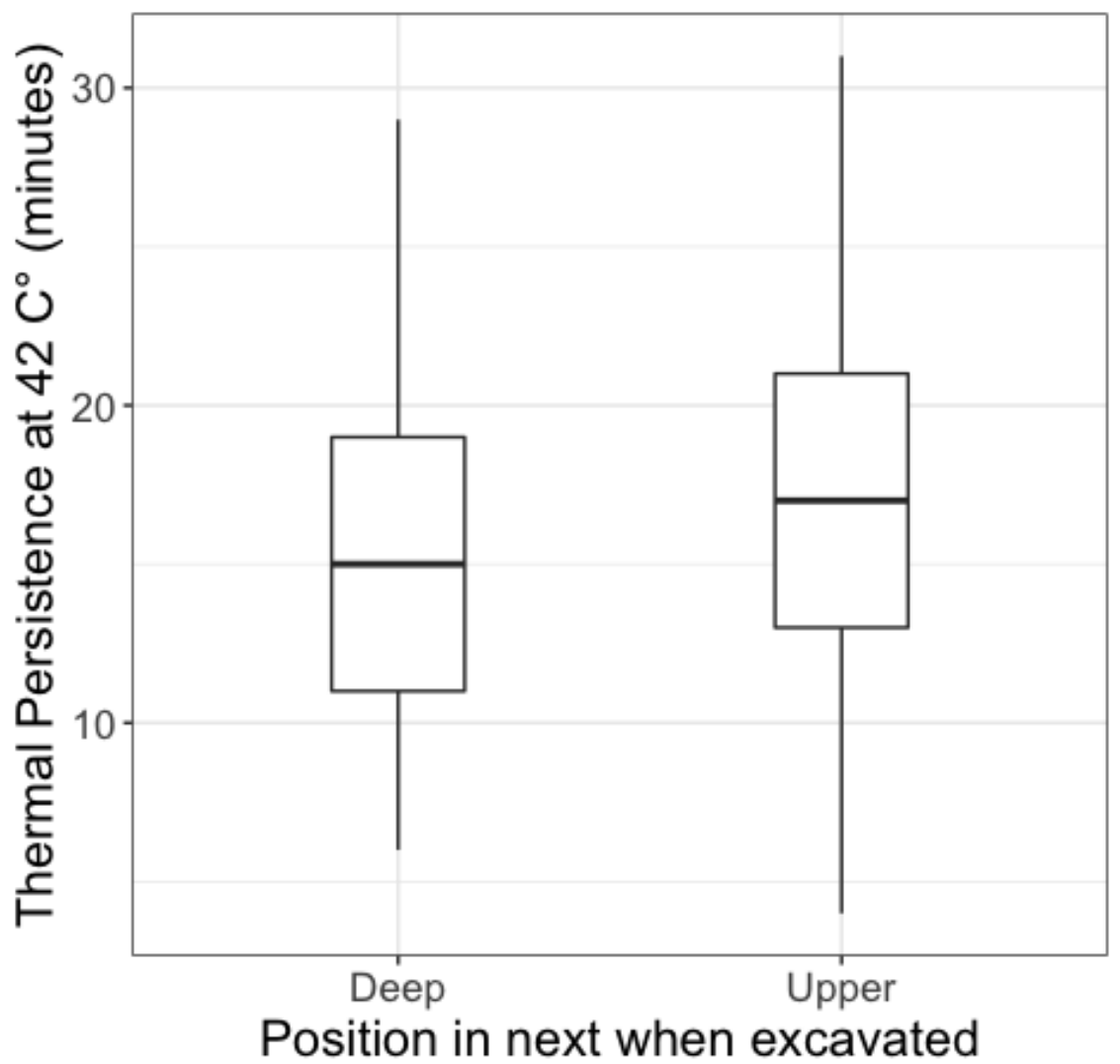

Figure 3. Circadian rhythm in ants. The thermal persistence was measured in individuals from colonies subjected to thermal treatments in the laboratory, assayed at daily thermal maxima and minima. Control 
ants are freshly caught foragers. Statistics are in Table 2.

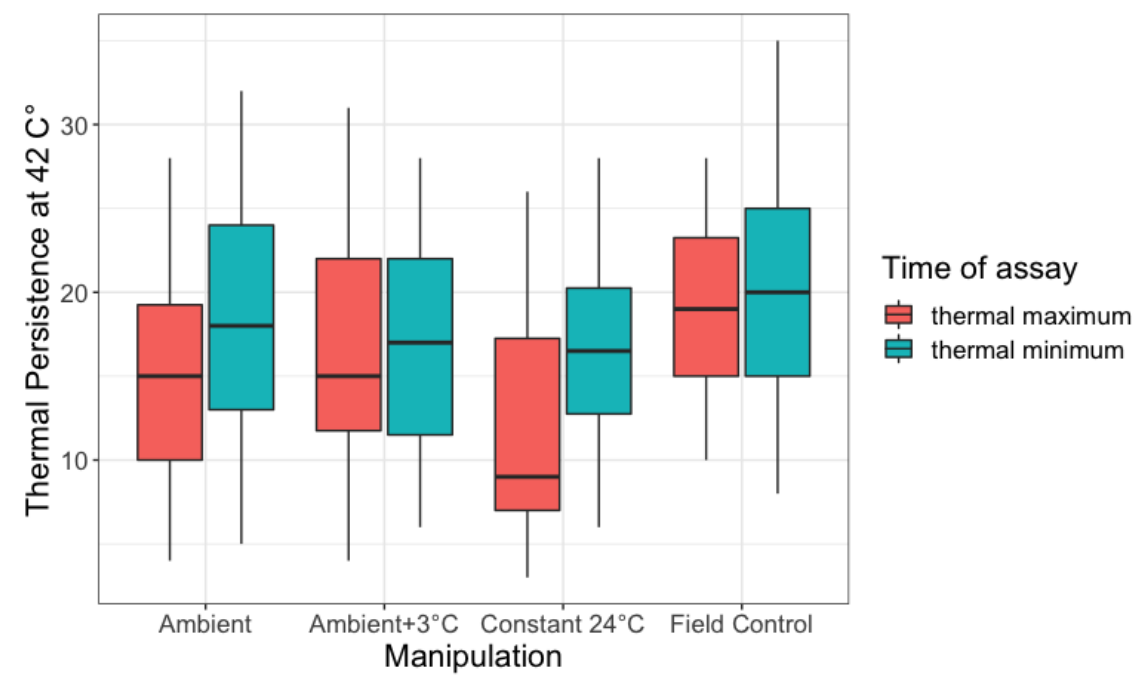

Table 1. The Marking Experiment results with a linear Cox Proportional Hazard model (Whole model Wald test $\left.\mathrm{X}^{2}=35.5, \mathrm{df}=4, \mathrm{p}<0.0001, \mathrm{~N}=399 ;\right)$

\begin{tabular}{llllll}
\hline & Coefficient $\beta$ & Hazard ratio & $\mathrm{SE}$ & $\mathrm{z}$ & $\mathrm{p}$ \\
\hline Afternoon foragers & & & & & \\
Morning foragers & -0.12 & 0.88 & 0.25 & -0.79 & 0.43 \\
Afternoon + morning foragers & -0.47 & 0.62 & 0.29 & -1.69 & 0.10 \\
Non-foragers & 0.36 & 1.43 & 0.13 & 2.60 & 0.009 \\
Position in nest & -0.38 & 0.68 & 0.11 & -3.47 & 0.0005 \\
\hline
\end{tabular}

Table 2. The Circadian Rhythm Experiment results with a linear Cox Proportional Hazard model (Whole model Wald test $\mathrm{X}^{2}=33.46, \mathrm{df}=4, \mathrm{p}<0.0001 ; \mathrm{N}=402$ )

\begin{tabular}{llllll}
\hline & Coefficient $\beta$ & Hazard ratio & SE & $\mathrm{z}$ & $\mathrm{p}$ \\
\hline Ambient & & & & & \\
Ambient $+3^{\mathrm{o}} \mathrm{C}$ & -.08 & 0.92 & 0.14 & -0.56 & 0.58 \\
Constant $24^{\mathrm{o}} \mathrm{C}$ & 0.32 & 1.38 & 0.14 & 2.36 & 0.02 \\
Control Foragers & -0.43 & 0.65 & 0.15 & -2.87 & 0.004 \\
Time of Day & -0.31 & 0.73 & 0.10 & -3.95 & 0.002 \\
\hline
\end{tabular}

